Corrigendum

\title{
Corrigendum to "Disability and common mental disorders: Results from the World Mental Health Survey Initiative Portugal" [Eur. Psychiatry 49 (2018) 56-61]
}

\author{
Ana Antunes ${ }^{\mathrm{a}, *}$, Diana Frasquilho ${ }^{\mathrm{a}}$, Sofia Azeredo-Lopes ${ }^{\mathrm{a}}$, Daniel Neto ${ }^{\mathrm{a}, \mathrm{b}}$, Manuela Silva ${ }^{\mathrm{a}}$, \\ Graça Cardoso ${ }^{a}$, José Miguel Caldas-de-Almeida ${ }^{a}$ \\ a Chronic Diseases Research Center (CEDOC), NOVA Medical School, Faculdade de Ciências Médicas, NOVA University of Lisbon, Lisbon, Portugal \\ ${ }^{\mathrm{b}}$ Hospital de Egas Moniz, Centro Hospitalar de Lisboa Ocidental, Lisbon, Portugal
}

In the Discussion section, where it is written "the societal cost of mental disorders in Portugal was higher in comparison to the results found by Alonso and colleagues in the group of high-income countries, with $20.2 \%$ of all days out of role in the last 30 days versus $11.3 \%$, respectively [11,24]" it should be read "the societal cost of mental disorders in Portugal was higher in comparison to the results found by Alonso and colleagues in the group of high-income countries, with $20.2 \%$ of all days out of role in the last 30 days versus $16.0 \%$, respectively $[11,24] "$ instead.

\footnotetext{
DOI of original article: http://dx.doi.org/10.1016/j.eurpsy.2017.12.004

* Corresponding author.

E-mail address: ana.antunes@nms.unl.pt (A. Antunes).
} 